\title{
Household Pandemic Response: The Socioeconomic Impact of COVID-19 on Migrant Households in India
}

\author{
S. Irudaya Rajan ${ }^{1}$, T. M. Sivadasan ${ }^{2 a}$, Reddy Sai Shiva Jayanth², Pooja Batra ${ }^{3}$ \\ 1 Department of Economics, The International Institute of Migration and Development (IIMAD), A1, Thittel House, Kanaka Nagar, Kowdiar, \\ Thiruvananthapuram 695003, India, 2 Department of Economics, Indian Institute of Management Kozhikode, Kunnamangalam, Kozhikode, Kerala, \\ India, ${ }^{3}$ Department of Economics, Indian Institute of Management Indore, Rau Pithampur Prabandh Shikhar, Indore, Madhya Pradesh, India \\ Keywords: kerala, international migration, internal migration, covid-19 \\ https://doi.org/10.46557/001c.25382
}

\section{Asian Economics Letters}

Vol. 3, Issue 2, 2022

We study the social impact of the COVID-19 pandemic and the coping strategies adopted by left-behind households comprising both internal and international migrants in Kerala, India. Using semi-structured telephone interviews with 52 households, we analyze the coping strategies these households have adopted to combat the effects of COVID-19 pandemic. The results suggest that the social vulnerability of migrant households could explain the differential impact of the pandemic on the remittance flows, consumption, food security, and livelihood of households.

\section{Introduction}

The COVID-19 pandemic has created misery for all segments of the population in terms of income loss, employment loss, and mental and physical agony. Specifically, migrants and remittance-dependent households across the world have experienced both the economic and social consequences of the pandemic (Bhagat et al., 2020). Changes in livelihood during the pandemic are primarily correlated with the socioeconomic background. The disadvantaged and marginalized of society are more prone to suffer from the disaster and bear the negative consequences of their social inequality (Deshpande \& Ramachandran, 2020). Hence, the pandemic has increased the double deprivation of migrant and remittance-dependent households.

Research has described the various aspects of social inequality in the differential impact of external shock. Studies focusing on developed and Western countries have highlighted the distinction between ethnic minorities and the majority population in dealing with the social impact of disaster and in the coping strategies of households. Most of the empirical research on the impact of natural shock on household economic activity has emphasized the loss of income and employment, including migration and the destruction of the home and other valuable assets (Elliott \& Pais, 2006; Zottarelli, 2008). Along a similar line, one strand of literature examines how pre-existing social inequality increases the difficulty of the recovery process of households and the economy from external economic shocks such as natural disasters and financial crises (Aptekar, 1990; Peacock et al., 1997). However, the litera- ture ascribes great importance to analyzing the differential impact of external shock on social groups in the context of natural disasters such as earthquakes, floods, and hurricanes, with less focus on the impact of health disasters and pandemics (Tang \& Li, 2021). A few studies analyze the impact of pandemics/epidemics on the economic activities of households in developing countries with social stratification. In a developing country such as India, the importance of migration and remittances in household economic activity is huge (Parida et al., 2015) and the pandemic has badly affected remittance-dependent households.

However, the role of social vulnerability in migrant households' differential impact on issues such as consumption, remittances, food security, networks, and debt and investment during the pandemic has not been as extensively explored. Furthermore, the literature has focused less on households' coping strategies during the disaster, especially when the socioeconomic background of households is marginalized. Thus, in this study, we aim to investigate how the socioeconomic vulnerability of migrants' families influences remittance patterns, consumption, employment, and food security. We also explore if the intensive margin and occupational diversity of migrants have had a differential impact on households' coping strategies.

Based on semi-structured telephonic interviews conducted with 52 households in Kerala, India, of both internal and international migrants, the current paper contributes to the literature by focusing on the social impact of the relative effects of the COVID-19 pandemic among remittancedependent households. Specifically, the paper analyzes the coping strategies adopted by these households in Kerala to 
combat the social vulnerability induced by the COVID-19 pandemic. Using individual- (migrants) and householdlevel information such as religion, age, education, migrant destination, duration of migration, and occupational diversity, we construct a measure of the social vulnerability of migrant left-behind households (LBHs). We then analyze the differential impact of social vulnerability on the economic outcome of the household, such as consumption, remittances, food security, and livelihood options during the pandemic. The study's findings suggest that the socioeconomic vulnerability of migrant households explains the differential impact of the pandemic on remittance flows, consumption, food security, and livelihood. Hence, this research extends theories of social inequality by analyzing the differential social impact of the pandemic on LBHs and their coping strategies. The study provides insights for policymakers in combating the vulnerability created by the pandemic among migrant and remittance-dependent households in India.

The remainder of the paper is structured as the following sections: a review of the literature is presented in Section II. Section III contains a description of the data. Section IV presents an analysis of the impact of COVID-19 and the coping strategies adopted by migrant LBHs. Section V concludes.

\section{Literature Review}

The theoretical literature on the decision to migrate argues that the migration of family members is a household decision, and migration is considered one of the risk mitigation strategies adopted by households in the developing world (Stark \& Bloom, 1985; Stark \& Taylor, 1989; Williams \& Baláž, 2012). In particular, the decision of who should migrate and decisions on remittances are made in consideration of family needs and household interactions (Ryan et al., 2009). Hence, the household considers migration and remittances to cope with the difficulties and income risk of those left behind.

The adoption of household coping strategies is pervasive among disadvantaged families and migrant populations because of the lower prevalence of formal institutional mechanisms to ensure support and minimize household risk (Gubhaju \& De Jong, 2009). Moreover, the empirical research shows that socioeconomic disadvantages increase the need for household coping strategies among migrants from developing and underdeveloped countries. Specifically, countries such as India and China having a larger rural population, and social stratification increases the negative consequences of disasters, when public transfers are constrained. Consequently, it has been reported that, in the outbreak of the COVID-19 pandemic, migrants in these countries have suffered more compared to other populations (Che et al., 2020; Rahman, 2020).

The empirical literature has widely acknowledged that the impact of the pandemic on households and individuals is correlated with preexisting vulnerabilities in the context of several economies. For example, Hardy and Logan (2020) enumerated the uneven distributional consequence of the COVID-19 pandemic on the U.S. population in the presence of racial and economic inequality. Similarly, socio-religious characteristics and, in particular, gender, demographic, and economic vulnerabilities have escalated the negative impact of the pandemic on the employment and livelihood of households in India and the world (Abraham et al., 2021; Agarwal, 2021; Couch et al., 2020; Deshpande \& Ramachandran, 2020; Kesar et al., 2021). Although these vulnerabilities have led to differential household outcomes of external shocks such as pandemics, there is scant literature on the household coping strategies of migration-dependent families. Notably, in the context of migration and remittance dependency, migrant households have faced a severe economic downturn due to loss of employment and income. Moreover, the informal nature of occupations and skill deficiency among migrants have constrained the benefits of public transfers, limiting their ability to combat the social impact of pandemic shocks. Therefore, the paper investigates the social impact of the pandemic on LBHs and their coping strategies in the context of Kerala, India.

\section{Study Description and Data}

To address the questions mentioned above, 52 in-depth semi-structured telephonic interviews were conducted with 23 internal migrant households and 29 international migrant households. ${ }^{1}$ The contacts were shared by the Centre for Development Studies, in Trivandrum, from the Kerala Migration Surveys of 2016 and 2018. Of 200 internal and 200 international migrants surveyed, we shortlisted 30 in each category using a random sampling method. Due to few rejections and unwillingness to participate in the study, we arrived at a final sample size of 52 households, including both internal and international migrant households. Our sample covers individuals from 13 of the 14 districts in Kerala. We interviewed the household heads of both the internal and international migrant families.

In the interviews, the participants (household heads) were asked to state their views and experiences before, during, and after the spread of COVID-19. The participants talked about their personal experiences and told stories about their entire families during the period. All the interviews were conducted in Malayalam, took place between August and September 2020, and lasted 10 to 15 minutes. All the interviews were translated into English and then

1 An internal or international migrant is the one who identifies “as any person (at least one or more) who was a usual resident of this household, migrated out of Kerala, and is still living outside Kerala for at least a year. Additionally, when probed about their current residence (within or outside India), those living outside India at the time of the survey were identified as international migrants and those living in India but outside Kerala as internal migrants.” 
transcribed. To guarantee the anonymity of the respondents in the analysis, we cite only the individual's gender, age, and a fictitious name with the quotations below.

\section{Discussion}

Our study was designed to capture the impact of COVID on internal and international migrant LBHs from various perspectives, such as employment, source of livelihood, lifestyle, and coping strategies during the lockdown. The ages of the household heads in our interviews ranged from 33 to 40 years, and more than three-fourths were men. The majority of the migrants from these LBHs stayed at their workplace and could not return home, due to, for example, worldwide cancellations of buses, trains, and flights, migrants' innate fears about job insecurity and uncertainty of arriving at their destination. Thus, most of these individuals remained in the state where they were employed. International migrants, primarily employed in the Gulf countries, returned home due to loss of employment, visa expiration, concerns for their families, and so forth.

\section{A. Remittance patterns}

For the majority of the households interviewed, remittances were the primary source of income. Close to 85 percent of the LBHs had received (either internal or international) remittances during the first wave of COVID, that is, in April, May, and June 2020. These remittances had been received without any delay. However, many migrants faced instances of salary cuts and job insecurity, which translated into lower remittances. The remaining households were deprived of any remittances during this period. To cope, they managed their expenses using mainly three sources: other family members' earnings, household savings, and pensions:

My son, who worked in a restaurant, in the Gulf, lost his job; thus, without money, we managed our livelihood through past savings and borrowings from friends and relatives.

Kozhikode, 52, male head of an international migrant household

\section{B. Consumption and food security}

About 55 percent and 80 percent of internal and international LBHs, respectively, reported no specific changes in lifestyle. From the onset of the pandemic, these households maintained a budget to control their expenses. Spending was minimal, as was consumption. Essential items were purchased, but in limited quantities. The LBHs reflected the impact of the pandemic by changing their food and eating habits. Expenditures on shopping, travel, and clothing plummeted. Eating habits quickly shifted from a meatbased to a plant-based diet to accommodate limited budgets. Movements were restricted due to lockdowns. Because of the financial crunch and restrictions on dining out, food consumption was also limited. The food expenditure of LBHs was managed by mobilizing past savings and borrowing money from relatives and friends. Food consump- tion was also reduced among return migrant households that had no earnings. The purchase and frequency of groceries dropped compared to the pre-pandemic period. Additionally, few families received food subsidies from the public distribution system.

\section{Employment}

The pandemic resulted in the loss of employment among the most vulnerable groups of the sample. Daily wage earners were thus forced to turn to informal sources to meet basic household needs. To make things worse, the respondents reported an increase in the prices of groceries and essentials. Further, we observed that, from April to September 2020, due to travel restrictions, willingness to travel to distant places for employment was reduced, with some looking for opportunity/prospects within their home state. More than half of the returning migrants perceived no attitudinal differences in migration outlook because of the pandemic:

My son received a salary cut due to the pandemic, our family expenses-we managed through the earnings of other members, past savings, and pension from the government.

Kollam, 52, male head of an internal migrant household

\section{Survival strategies}

The survey respondents reported having no new jobs and acute difficulty obtaining work during the pandemic period. Only a handful of migrants were given return tickets by their employers. Other migrants managed their expenses through past savings and informal borrowing. Migrants working in the service sector (e.g., restaurants, hotels, tourism) suffered, since most reported losing their job and moving back to Kerala in July 2020. Those migrants who had been looking for job opportunities in Kerala remained unemployed:

\section{Due to no income from my migrant son due to his salary suspension, we were dependent on government subsidies through the Public Distribution System and also borrowed money from self-help groups for our living. \\ Kannur, 48, female household head of an international migrant household}

The results show that households that depend on migrants other than those who worked as daily wage labor took a lesser hit. They were able to cope with the first wave of the pandemic either by tapping into their savings or through informal borrowing. Most of the internal and international migrant LBHs depend on remittances for their source of livelihood. Those unable to receive remittances faced severe disruptions to their housing situation and financial conditions.

\section{Conclusion}

The pandemic has made an indelible mark on everyone's lives. Numerous studies have investigated its impact among various sections of society. In this study, we mainly focus 
on the impact on the lives of migrants. More specifically, we explore how the socioeconomic vulnerability of migrant families influences their remittance patterns, consumption, employment, and food security. Further, we study if the intensive margin and occupational diversity of migrants have had a differential impact on the coping strategies of households. Analysis of the survey participants' narratives provides a comprehensive understanding of migrant LBHs during the spread of COVID-19. The discussions reveal deliberate choices made by the household head to maintain and secure the well-being of household members during the external shock.

This study has several policy and research implications. Policymakers could use the results for targeted aid provision and to help compensate households for damage caused by the pandemic. The findings also suggest that the impact of the pandemic has not been uniform. It thus becomes necessary for policymakers to take suitable actions to address the concerns faced by various groups of people in tackling the crisis of food security and the loss of employment and livelihood. The study also highlights the importance of considering the differences in the extent of shock for different kinds of LBHs.
We identity two limitations of our study. First, the current study focuses only on migrants and LBHs in Kerala. While this can be considered a small sample, our study sets the foundation for additional research. Second, our sample focuses on international migrants mostly based out of the Gulf countries. Future research could empirically explore the impact of the pandemic on different forms of migrants, based on their incidence and factors such as level of education, mental health, availability of resources, and social networks. Further, we predict immense scope for future studies across various other states/countries and on migrants returning from various regions besides the Gulf states.

\section{Acknowledgment}

We acknowledge the support from Dr. Sunitha S for her tedious efforts in compiling and providing us with the migrants' data.

Submitted: May 01, 2021 AEST, Accepted: May 25, 2021 AEST 


\section{References}

Abraham, R., Basole, A., \& Kesar, S. (2021). Tracking Employment Trajectories In the Covid-19 Pandemic: Evidence from Indian Panel Data. CSE Working Paper \#35.

Agarwal, B. (2021). Livelihoods in COVID times: Gendered perils and new pathways in India. World Development, 139, 105312. https://doi.org/10.1016/j.w orlddev.2020.105312

Aptekar, L. (1990). A comparison of the bicoastal disasters of 1989. Behavior Science Research, 24(1-4), 73-104. https://doi.org/10.1177/10693971900240010 $\underline{5}$

Bhagat, R. B., Reshmi, R. S., Sahoo, H., Roy, A. K., \& Govil, D. (2020). The COVID-19, migration and livelihood in India: Challenges and policy issues. Migration Letters, 17(5), 705-718. https://doi.org/10.3 3182/ml.v17i5.1048

Che, L., Du, H., \& Chan, K. W. (2020). Unequal pain: A sketch of the impact of the Covid-19 pandemic on migrants' employment in China. Eurasian Geography and Economics, 61(4-5), 448-463. https://doi.org/10.1 $\underline{080 / 15387216.2020 .1791726}$

Couch, K. A., Fairlie, R. W., \& Xu, H. (2020). The impacts of COVID-19 on minority unemployment: First evidence from April 2020 CPS microdata. SSRN Electronic Journal, 3604814. https://doi.org/10.2139/ss $\underline{\text { rn.3604814 }}$

Deshpande, A., \& Ramachandran, R. (2020). Is Covid-19 "The Great Leveler"? The Critical Role of Social Identity in Lockdown-induced Job Losses (No. 622). GLO Discussion Paper.

Elliott, J. R., \& Pais, J. (2006). Race, class, and Hurricane Katrina: Social differences in human responses to disaster. Social Science Research, 35(2), 295-321. http s://doi.org/10.1016/j.ssresearch.2006.02.003

Gubhaju, B., \& De Jong, G. F. (2009). Individual versus household migration decision rules: Gender and marital status differences in intentions to migrate in South Africa. International Migration, 47(1), 31-61. ht tps://doi.org/10.1111/j.1468-2435.2008.00496.x

Hardy, B. L., \& Logan, T. D. (2020). Racial economic inequality amid the COVID-19 crisis. The Hamilton Project, Essay, 17.
Kesar, S., Abraham, R., Lahoti, R., Nath, P., \& Basole, A. (2021). Pandemic, informality, and vulnerability: Impact of COVID-19 on livelihoods in India. Journal of Development Studies/Revue Canadienne D'études du Développement, 1-20.

Parida, J. K., Mohanty, S. K., \& Raman, K. R. (2015). Remittances, household expenditure and investment in rural India: Evidence from NSS data. Indian Economic Review, 79-104.

Peacock, W. G., Morrow, B. H., \& Gladwin, H. (Eds.). (1997). Hurricane Andrew: Ethnicity, gender, and the sociology of disasters. Psychology Press.

Rahman, S. Y. (2020). 'Social distancing' during COVID-19: The metaphors and politics of pandemic response in India. Health Sociology Review, 29(2), 131-139. https://doi.org/10.1080/14461242.2020.179 $\underline{0404}$

Ryan, L., Sales, R., Tilki, M., \& Siara, B. (2009). Family strategies and transnational migration: Recent Polish migrants in London. Journal of Ethnic and Migration Studies, 35(1), 61-77. https://doi.org/10.1080/136918 $\underline{30802489176}$

Stark, O., \& Bloom, D. E. (1985). The new economics of labor migration. The American Economic Review, 75(2), 173-178.

Stark, O., \& Taylor, J. E. (1989). Relative deprivation and international migration. Demography, 26(1), 1-14. https://doi.org/10.2307/2061490

Tang, S., \& Li, X. (2021). Responding to the pandemic as a family unit: Social impacts of COVID-19 on rural migrants in China and their coping strategies. Humanities and Social Sciences Communications, 8(1), 1-11. https://doi.org/10.1057/s41599-020-00686-6

Williams, A. M., \& Baláž, V. (2012). Migration, risk, and uncertainty: Theoretical perspectives. Population, Space and Place, 18(2), 167-180. https://doi.org/10.10 02/psp.663

Zottarelli, L. K. (2008). Post-Hurricane Katrina Employment Recovery: The Interaction of Race and Place. Social Science Quarterly, 89(3), 592-607. http s://doi.org/10.1111/j.1540-6237.2008.00550.x 